\title{
Use of external Indicators to Evaluate Stress of Largemouth (Micropterus salmoides) and Smallmouth (M. dolomieu) Bass at Tournaments
}

\author{
George A. Maynard ${ }^{1,}{ }^{*}$, Timothy B. Mihuc ${ }^{1}$, Rachel E. Schultz ${ }^{2}$, V. Alex Sotola ${ }^{1}$, Alejandro J. \\ Reyes ${ }^{1}$, Mark H. Malchoff ${ }^{3}$ and Danielle E. Garneau ${ }^{2}$ \\ ${ }^{1}$ Lake Champlain Research Institute at SUNY Plattsburgh, USA \\ ${ }^{2}$ Center for Earth and Environmental Science, SUNY Plattsburgh, USA \\ ${ }^{3}$ Lake Champlain Sea Grant, SUNY Plattsburgh, USA
}

\begin{abstract}
The popularity of catch and release tournaments targeting largemouth (Micropterus salmoides) and smallmouth (M. dolomieu) bass has continued to increase over the past few decades. In 2008, Lake Champlain hosted 95 tournaments, including several large-scale events hosted in Plattsburgh, NY. As in any catch-and-release fishery, released fish exhibit varying amounts and types of stress, potentially generating sub-lethal population-level impacts. Due to the large volume of fish that move through catch and release tournaments, blood chemistry analysis is generally outside of the temporal and financial constraints of tournament organizers. External indicators of stress can be used to determine stress levels in large numbers of fish. We adapted some of these indicators (e.g., wounding, response to stimuli) from research in marine and commercial fisheries to assess fish stress following weigh-in at Plattsburgh-based catch and release tournaments. Additionally, we collected data including fish measurements, lake temperature, fish capture locations, and information on tournament handling practices to determine which external factors influenced fish stress levels. Generalized linear models showed increased likelihood of elevated stress levels as a positive function of ambient lake temperature, fish size, and livewell transport distance. Comparison of results with existing research on bass stress are consistent with our models, indicating that external signs of stress can be used to evaluate black bass stress levels at catch-and-release tournaments.
\end{abstract}

Keywords: Catch and release, largemouth; Micropterus, smallmouth; stress, tournaments.

\section{INTRODUCTION}

Black bass (Micropterus spp.) are some of the most sought-after sport fish in North America. In the 2007 New York Statewide Angler Survey, 33\% of anglers rated black bass as their top target fish, and $75 \%$ of anglers ranked black bass as one of their top five target fish [1,2]. Many bass anglers participate in catch-and-release fishing tournaments, ranging from local events with less than a dozen boats to international events with hundreds of boats. A recent report from Connecticut highlights the exponential growth in popularity of tournament bass fishing over the past few decades. In the $1980 \mathrm{~s}$, Connecticut hosted an average of 150 tournaments per year. That number increased to 600 tournaments per year in the 1990s, and in 2000, Connecticut hosted over 800 tournaments [2]. Ranked as one of the top ten bass fishing lakes in the United States [3], Lake Champlain has seen heavy tournament fishing pressure in recent years. In 2008, communities on Lake Champlain hosted 95 tournaments [4].

It is well documented that angling fish can have negative impacts on fish health and survival [5-8]. Stress levels can be influenced by a variety of factors including holding time

*Address correspondence to this author at the Center for Earth and Environmental Science, SUNY Plattsburgh, USA; Tel: (860)859-7823;

E-mail: galphonsemaynard@gmail.com
[9], air exposure [10], livewell conditions [11], fish size [12], and water temperature [13]. Recovery time from physiological stress for a variety of fish species ranges from 8 to 12 hours, depending on post-release conditions [14]. Immediate mortality from angling stress (i.e. angling induced injury, barotrauma, or exhaustion) is usually negligible in centrarchids, except in cases of extreme temperatures $[15,16]$; however, delayed mortality can still present a problem for catchand-release anglers. Research into fish stress levels can help determine when and why fish experience the most stress, allowing catch-and-release anglers to take corrective actions and minimize sub-lethal impacts of angling on fish.

Much of the current research on sub-lethal stress in fish uses blood chemistry analysis to gauge stress levels [16-18]. However, recent research also suggests that blood chemistry alone might not be the best indicator of fish stress (i.e. angling induced injury, barotrauma, or exhaustion) and delayed (within five days of angling) mortality. In numerous studies, high levels of angling or hauling (transport in a livewell or other enclosure) induced stress was linked to an increased likelihood of delayed mortality $[8,9,15]$. Mortality due to air exposure did not correspond to changes in blood chemistry among commercially captured Pacific halibut (Hippoglossus stenolepis) [10]. A study of northern pike (Esox lucius) response to angling and handling showed that despite a dearth of significant changes in blood chemistry variables, 
Table 1. Physical Indicators of Stress Fish were Evaluated for

\begin{tabular}{|c|c|c|}
\hline $\mathrm{BF}$ & Bloody fins & Hemorrhaging present in fins \\
\hline $\mathrm{DE}$ & Absence of dorsal fin erection & Fins do not erect when fish is restrained \\
\hline $\mathrm{EE}$ & Esophageal eversion & Eversion of esophageal tissue into buccal cavity \\
\hline HW & Hook wound & Hook embedded in fish or noticeable wounding in or around mouth \\
\hline LW & Lamprey wound & Noticeable circular wounding from sea lamprey (Petromyzon marinus) \\
\hline $\mathrm{MC}$ & Absence of mouth clamp & Mouth does not clamp shut when lifted or opened \\
\hline RR & Absence of restraint resistance & Fish does not exhibit muscle flex to escape \\
\hline TA & Tight abdomen & Abdomen swollen, feels tight when touched \\
\hline
\end{tabular}

fish that were angled and handled for greater amounts of time took longer to recover post-release [19]. Research on black bass also suggests that blood chemistry responses to air exposure are inconsistent [16]. Blood chemistry analysis can be time consuming, expensive, and demanding of technical skills, making it impractical for use with large numbers of fish in a field (non-laboratory) setting. Recent studies conducted in the marine environment to evaluate fish stress following capture by trawling suggest that externally observable stress indicators such as wounding [20] and response to stimuli [21] can be used to predict mortality in a variety of fish species.

We set out to investigate the possibility of using external signs and behaviors as proxy indicators for the evaluation of stress in largemouth (Micropterus salmoides) and smallmouth (M. dolomieu) bass. If shown to be viable, such proxy measures of stress could be used by researchers, management agencies, and tournament directors to better manage bass stress levels (and thus, survival) associated with tournament angling, weigh-in, and subsequent release.

\section{MATERIALS AND METHODS}

Using metrics adopted from Davis [21] and Campbell et al. [22], we assessed fish for a battery of physical indicators of stress (Table 1) at nine catch-and-release bass tournaments based in Plattsburgh, NY. A typical catch-and-release tournament proceeds as follows: anglers depart from a starting point and spend several hours (up to 8) fishing. Fish are captured and held in a livewell onboard each fishing boat. Each angler may keep up to five fish, and usually each angler is paired with a co-angler. As many as ten fish may be held in each boat. The boats return to a designated weigh-in location where fish are removed from livewells and held in water-filled plastic bags submerged in a holding tank while the anglers wait for their turn to weigh in. When that time comes, anglers carry the plastic bags to a scale, where fish are removed from the bags and weighed. After weighing-in, fish are brought to a release boat. Once the release boat is full to capacity, the fish are transported to the release point and dumped back into the lake.

We collected fish from anglers between the weigh-in stage and the release boat; fish evaluation occurred in oxygenated holding tanks with a flow-through rate of 378 liters / hour. Lake temperature was recorded for each individual tournament day (for a total of 13 temperature records). Each stress indicator was scored as present or absent ( 1 or 0$)$. We assigned each fish a capture location based on information collected from cooperating anglers. Using Quantum GIS v1.8.0 [23], we assigned distances from each capture location to the weigh-in. Additionally, we measured temperature ranges at holding tanks used by Lake Champlain Research Institute (LCRI) staff to assess fish, tournament holding tanks (where fish are kept between the livewell and weighin), and holding tanks on the release boat (where fish are kept after weigh-in) on four tournament days. All data were managed using a database developed in Microsoft Access v12.

To test for variable independence, we tested for correlations between stress indicators (package "Hmisc"; Table 2). Correlations broke the indicators into two distinct groups and revealed only two independent indicators. Tight abdomen, exopthalmia, and ocular emphysema were grouped into "barotrauma indicators." If a fish exhibited any one of these three indicators, it was counted as exhibiting barotrauma. Bloody fins, hook wounds, fin damage, absence of dorsal erection, absence of mouth clamp, and absence of restraint resistance were grouped into "wounds and indicators of exhaustion." If a fish exhibited any one of these six indicators, 
Table 2. Correlation Table Showing Relationships between Stress Indicators. Statistical Significance is Designated at the Following Levels: $\mathbf{p}<0.05(*), \mathbf{p}<0.01(* *), \mathbf{p}<0.001(* * *)$.

\begin{tabular}{|c|c|c|c|c|c|c|c|c|c|c|c|}
\hline TA & PE & BF & OE & $\mathbf{E E}$ & DE & MC & RR & HW & FD & $\mathbf{L W}$ & \\
\hline \multirow[t]{2}{*}{1} & $0.15^{* * *}$ & -0.02 & $0.05^{* *}$ & -0.01 & $0.06^{* *}$ & -0.04 & -0.03 & -0.01 & -0.04 & -0.02 & $\mathrm{TA}$ \\
\hline & 1 & -0.02 & $0.06^{* *}$ & 0.00 & -0.02 & -0.01 & 0.00 & -0.02 & 0.00 & -0.01 & $\mathrm{PE}$ \\
\hline & & 1 & $0.10^{* * *}$ & -0.01 & $0.08^{* * *}$ & $0.07^{* * *}$ & -0.03 & $0.14^{* * *}$ & $0.36^{* * *}$ & -0.03 & $\mathrm{BF}$ \\
\hline & & & 1 & -0.01 & $0.07^{* * *}$ & 0.03 & 0.03 & 0.01 & $0.10^{* * * *}$ & -0.01 & $\mathrm{OE}$ \\
\hline & & & & 1 & -0.01 & 0 & 0.01 & -0.01 & 0.02 & -0.01 & $\mathrm{EE}$ \\
\hline & & & & & 1 & $0.16^{* * *}$ & $0.15^{* * *}$ & $0.07^{* * *}$ & $0.10^{* * *}$ & -0.04 & $\mathrm{DE}$ \\
\hline & & & & & & 1 & $0.46^{* * *}$ & 0.03 & $0.15^{* * *}$ & -0.02 & $\mathrm{MC}$ \\
\hline & & & & & & & 1 & -0.02 & 0.02 & 0.00 & RR \\
\hline & & & & & & & & 1 & $0.2^{* * *}$ & -0.02 & HW \\
\hline & & & & & & & & & 1 & -0.03 & FD \\
\hline & & & & & & & & & & 1 & LW \\
\hline
\end{tabular}

Table 3. Summary of Models for Barotrauma, Wounding/Exhaustion, lamprey Wounds, and Esophageal Eversion. Models were Compared using Akaike's Information Criterion (AIC). The Lowest AIC in each Category is the Best Fitting Model. Models with dAIC $<2$ are Considered Reasonable Alternatives. If no Models are Significantly Better than the Null (random) Model, the Relationship is Meaningless

\begin{tabular}{|c|c|c|c|c|c|c|c|}
\hline \multirow[b]{2}{*}{ Model } & \multirow[b]{2}{*}{$\mathbf{k}$} & \multicolumn{3}{|c|}{ Smallmouth Bass } & \multicolumn{3}{|c|}{ Largemouth Bass } \\
\hline & & AIC & $\Delta \mathrm{AIC}$ & Weight & AIC & $\Delta \mathbf{A I C}$ & Weight \\
\hline Baro Null model & 0 & 795.97 & 5.4 & 0.02 & 773.02 & 46.66 & $<0.001$ \\
\hline Baro $\sim$ SqrtDist & 1 & 797.14 & 6.57 & 0.01 & 763.28 & 36.92 & $<0.001$ \\
\hline Baro $\sim$ Temp & 1 & 791.48 & 0.91 & 0.23 & 729.97 & 3.61 & 0.07 \\
\hline Baro $\sim$ Length & 1 & 794.73 & 4.16 & 0.04 & 771.07 & 44.71 & $<0.001$ \\
\hline Baro $\sim$ SqrtDist + Temp & 2 & 792.75 & 2.18 & 0.12 & 726.36 & 0 & 0.42 \\
\hline Baro $\sim$ SqrtDist + Length & 2 & 796.08 & 5.51 & 0.02 & 763.72 & 37.36 & $<0.001$ \\
\hline Baro $\sim$ Temp + Length & 2 & 790.57 & 0 & 0.36 & 728.89 & 2.53 & 0.12 \\
\hline Baro $\sim$ SqrtDist + Temp + Length & 3 & 792.02 & 1.45 & 0.17 & 726.56 & 0.2 & 0.38 \\
\hline WoundEx Null model & 0 & 1099.4 & 29.1 & $<0.001$ & 569.25 & 51.62 & $<0.001$ \\
\hline WoundEx $\sim$ SqrtDist & 1 & 1091.8 & 21.5 & $<0.001$ & 538.94 & 21.31 & $<0.001$ \\
\hline WoundEx $\sim$ Temp & 1 & 1078.7 & 8.4 & 0.01 & 547.88 & 30.25 & $<0.001$ \\
\hline WoundEx $\sim$ Length & 1 & 1100.4 & 30.1 & $<0.001$ & 556.75 & 39.12 & $<0.001$ \\
\hline WoundEx $\sim$ SqrtDist + Temp & 2 & 1070.3 & 0 & 0.66 & 522.42 & 4.79 & 0.08 \\
\hline
\end{tabular}


Table 3. contd...

\begin{tabular}{|c|c|c|c|c|c|c|c|}
\hline \multirow[b]{2}{*}{ Model } & \multirow[b]{2}{*}{$\mathbf{k}$} & \multicolumn{3}{|c|}{ Smallmouth Bass } & \multicolumn{3}{|c|}{ Largemouth Bass } \\
\hline & & AIC & $\Delta \mathrm{AIC}$ & Weight & AIC & $\Delta \mathrm{AIC}$ & Weight \\
\hline WoundEx $\sim$ Temp + Length & 2 & 1080.0 & 9.7 & 0.005 & 535.72 & 18.09 & $<0.001$ \\
\hline LW Null model & 0 & 299.48 & 7.64 & 0.01 & 266.46 & 0 & 0.29 \\
\hline $\mathrm{LW} \sim$ SqrtDist & 1 & 301.18 & 9.34 & 0.004 & 267.95 & 1.49 & 0.13 \\
\hline $\mathrm{LW} \sim \mathrm{Temp}$ & 1 & 301.33 & 9.49 & 0.004 & 267.31 & 0.85 & 0.19 \\
\hline LW $\sim$ SqrtDist + Length & 2 & 293.31 & 1.47 & 0.22 & 269.48 & 3.02 & 0.06 \\
\hline LW $\sim$ Temp + Length & 2 & 295.02 & 3.18 & 0.09 & 269.01 & 2.55 & 0.08 \\
\hline LW $\sim$ SqrtDist + Temp + Length & 3 & 293.54 & 1.7 & 0.19 & 270.48 & 4.02 & 0.03 \\
\hline EE Null model & 0 & 31.732 & 0 & 0.28 & 56.525 & 0.663 & 0.19 \\
\hline $\mathrm{EE} \sim$ SqrtDist & 1 & 33.729 & 1.997 & 0.10 & 58.102 & 2.24 & 0.08 \\
\hline $\mathrm{EE} \sim \mathrm{Temp}$ & 1 & 31.987 & 0.255 & 0.25 & 55.862 & 0 & 0.26 \\
\hline $\mathrm{EE} \sim$ SqrtDist + Temp + Length & 3 & 33.921 & 2.189 & 0.09 & 58.34 & 2.478 & 0.07 \\
\hline
\end{tabular}

it was counted as exhibiting wounds and exhaustion. Lamprey wounds and esophageal eversion were not correlated with any other stress indicators, so each was evaluated individually.

In order to reduce the skewed nature of the distance traveled data, we used a square-root transformation to tighten the distribution [24]. To determine the effects of water temperature, fish length, and distance traveled in a livewell on fish stress, we used generalized linear modeling (GLM) [25]. We ran eight logit link GLMs for each indicator group (barotrauma, wounding/exhaustion, esophageal eversion, and lamprey wounds) for each species, totaling 64 models (Table 3). Following model creation, we used AIC values to determine the most appropriate models for each indicator group ( $\triangle \mathrm{AIC}$ $\left.=\mathrm{AIC}-\mathrm{AIC}_{\min } \leq 2\right)$. Stress indicators for which the null model had the lowest $\mathrm{AIC}$ value or for which $\mathrm{AIC}_{\text {null }}-\mathrm{AIC}$ $\min \leq 2$ were treated as being insignificant. To determine the if tournament handling practices were exacerbating stress via temperature shock, we tested for significant differences in temperature between different pieces of tournament infrastructure using Mann-Whitney U tests. All statistical analysis was conducted using the R Project for Statistical Computing v2.14.1 [26] in the RStudio v0.97 environment [27].

\section{RESULTS}

In total, we analyzed 1245 smallmouth bass and 1349 largemouth bass. A majority of largemouth bass exhibited bloody fins (64\%), fin damage (59\%), and / or an absence of dorsal fin erection (69\%; Fig. 1). More than one quarter of largemouth bass exhibited hook wounds $(36 \%)$ and / or an absence of mouth clamp (28\%). A majority of smallmouth bass exhibited bloody fins (55\%). Nearly half of smallmouth bass exhibited an absence of dorsal erection (49\%) and over a quarter exhibited fin damage (33\%). Lake temperatures on tournament days ranged from $15.2^{\circ} \mathrm{C}$ to $22.2^{\circ} \mathrm{C}$. Total lengths (TL) of fishes ranged from $300 \mathrm{~mm}$ to $545 \mathrm{~mm}$. 


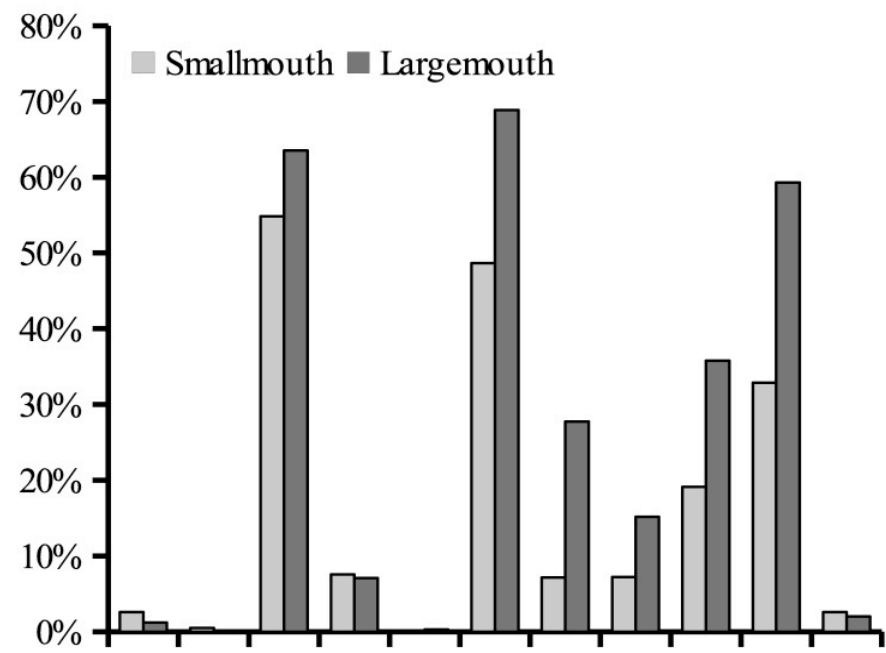

TA PE BF OE EE DE MC RR HW FD LW

\section{Stress Indicator}

Fig. (1). Percent occurrence of stress indicators by species. Stress indicators are tight abdomen (TA), exopthalmia (PE), bloody fins (BF), ocular emphysema (OE), esophageal eversion (EE), absence of dorsal fin erection (DE), absence of mouth clamp (MC), absence of restraint resistance (RR), hook wounds (HW), fin damage (FD), and lamprey wounds (LW).

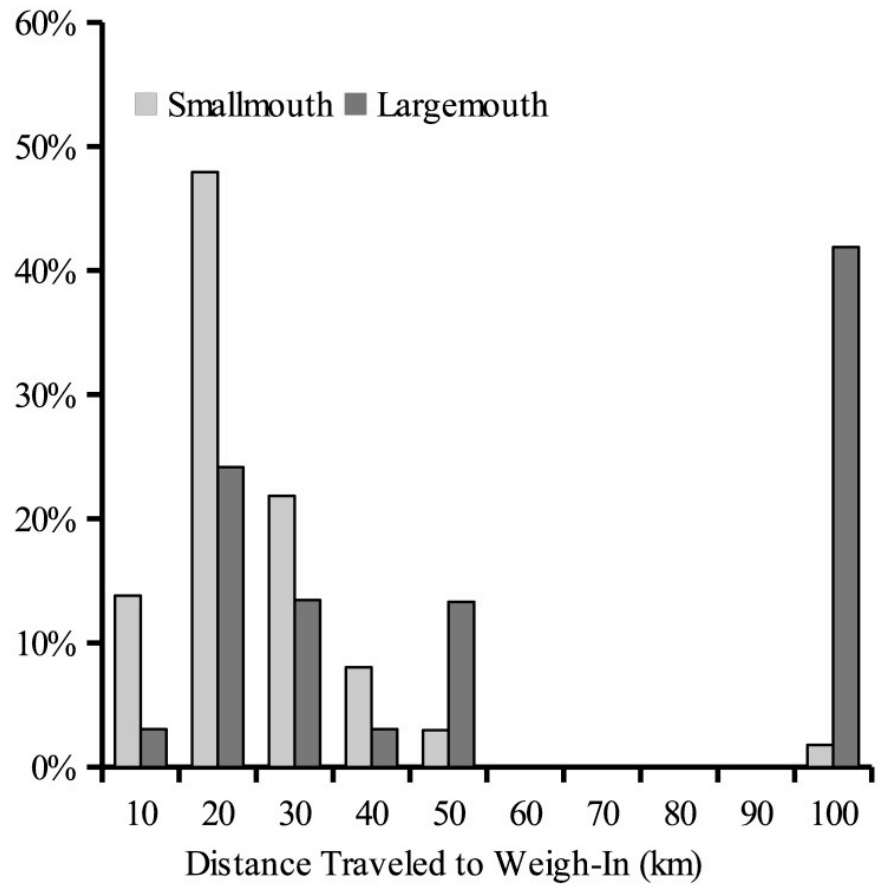

Fig. (2). Percent of fish traveling certain distances to weigh in. Most smallmouth bass were captured within $50 \mathrm{~km}$ of Plattsburgh, while nearly half of all largemouth bass were captured $100 \mathrm{~km}$ from Plattsburgh.

Fishes were transported as little as $0.3 \mathrm{~km}$ and as much as $100 \mathrm{~km}$ from point of capture to the weigh-in station (Fig. 2).

Barotrauma indicators were defined as tight abdomen, exopthalmia, or ocular emphysema. In both smallmouth and largemouth bass, the most important predictor of barotrauma was lake temperature (Table 4). Fishes captured on warmer days were more likely to exhibit indicators of barotrauma $\left(\mathrm{SM} \mathrm{p}_{\mathrm{avg}}=0.0126 ; \mathrm{LM} \mathrm{p}_{\mathrm{avg}}<0.01\right)$. For largemouth bass, fish transported farther were also more likely to exhibit barotrauma indicators $\left(\mathrm{p}_{\mathrm{avg}}=.0305\right)$. There was a trend towards longer smallmouth bass being more likely to exhibit barotrauma $\left(\mathrm{p}_{\mathrm{avg}}=0.09\right)$, but it was not statistically significant.

Distance traveled, fish length, and water temperature were not significant predictors of the occurrence of esophageal eversion. None of the models generated for this stress indicator were significantly better than the null (random) model (Table 4). There were also no significant predictors of the occurrence of lamprey wounds in largemouth bass. In smallmouth bass, however, longer fish were more likely to be victims of a lamprey attack $(\mathrm{p}<0.01)$. 


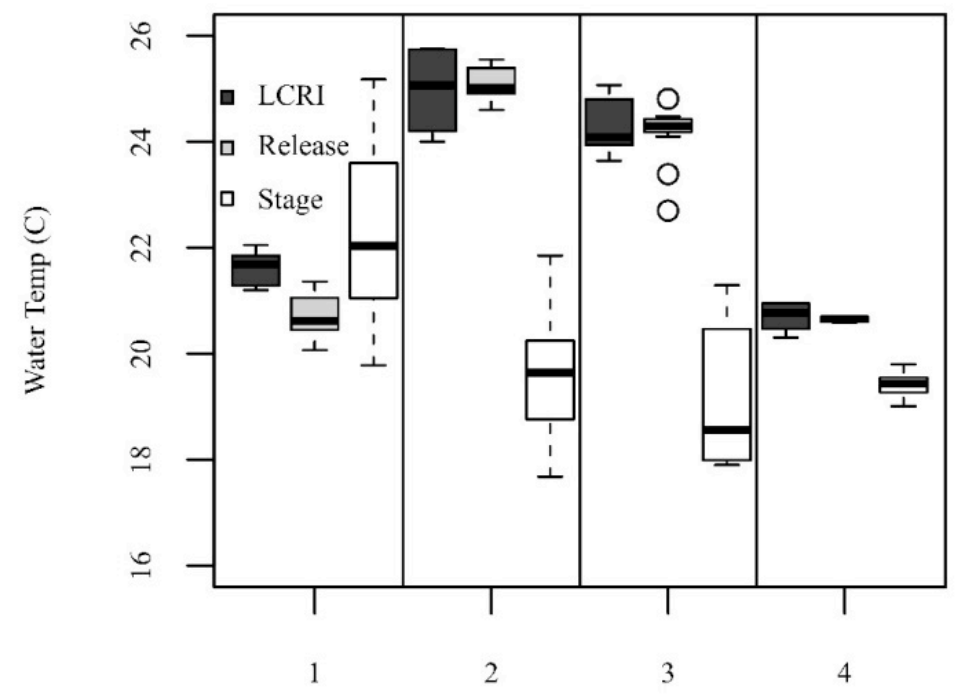

Tournament

Fig. (3). Boxplot showing ranges of water temperatures in tournament infrastructure on four tournament days. "LCRI" refers to tanks used by LCRI staff to monitor fish stress. "Release" refers to holding tanks on the release boat, and "Stage" refers to holding tanks at the weigh-in facility. Tournament 2 had the highest in situ lake temperature, followed by Tournament 3 and Tournament 4 . Tournament 1 had the lowest in situ lake temperature. All water temperatures were measured in ${ }^{\circ} \mathrm{C}$.

Bloody fins, hook wounds, fin damage, absence of dorsal spine erection, absence of mouth clamp, and absence of restraint resistance were all counted towards scoring fish as "wounded or exhausted." Lake temperature and distance traveled in a livewell were significant predictors of wounding and exhaustion (Table 4). Fishes captured on warmer days were more likely to be wounded or exhausted by the time they reached weigh in (SM $\mathrm{p}_{\text {avg }}<0.01 ; \mathrm{LM} \mathrm{p}<0.01$ ). Additionally, the farther fishes were transported, the more likely they were to exhibit wounds or indicators of exhaustion at the weigh-in (SM p avg $<0.01 ; \mathrm{LM} \mathrm{p}<0.01)$. Another important predictor of wounding and exhaustion in largemouth bass was fish length. Longer fish were more likely to be wounded or exhausted $(\mathrm{p}<0.01)$.

We sampled water temperature ranges in tournament holding tanks (where fish are kept between livewell and weigh-in), LCRI tanks (where we evaluated fish), and release boat tanks (where fish are kept between weigh-in and release) on four tournament days in 2012 (Fig. 3). Tournament holding tanks were treated with ice by tournament staff on the three warmest days. Temperatures of LCRI tanks were similar to release boat temperatures on all four days. Temperatures of the tournament holding tanks were lower than those of the release boat $(p<0.001)$ and LCRI tanks ( $p$ $<0.001)$ on the three warmest days when ice was used.

\section{DISCUSSION}

The purpose of this study was to evaluate whether or not physical indicators of stress could be used to reliably assess black bass condition at catch and release tournament events.

Fishes of both species were more likely to exhibit barotrauma during tournaments with higher lake temperatures. Incidences of barotrauma increase dramatically if fish are angled from depths $>5-6 \mathrm{~m}[28,29]$. Both conventional fish- eries management texts [30,31] and research into barotrauma [29] indicate that black bass move into epilimnetic waters in the summer months. As the epilimnion continues to warm over the course of the summer season, black bass, especially smallmouth bass, may retreat to deeper water near the thermocline [32]. In many areas of Lake Champlain, the thermocline sets up at a depth greater than 10m [LCRI, unpublished data], well beyond the 5-6m threshold for increased likelihood of barotrauma. Thus, one would expect to see higher levels of barotrauma during the warmest periods of the year.

In largemouth bass, distance traveled was also a predictor of barotrauma, with fish that were transported greater distances being more likely to exhibit signs of barotrauma. Tournament-captured fish are likely to have high levels of plasma lactate due to intense exertion $[29,33,34]$. In these studies, aspartate aminotransferase (AST) and other blood chemistry indicators of stress were highest among fish with severe barotrauma. Fish with severe barotrauma were often those that died post-release. High AST concentrations indicate tissue damage, and internal damage to fish experiencing barotrauma may be increased by the amount of time spent in a livewell on the surface [33]. According to our results, largemouth bass that spent longer time in a livewell were more likely to exhibit indicators of barotrauma than largemouth bass that traveled less time in a livewell. A study on Australian bass (Macquaria novemaculeata) found that the severity of barotrauma increases the longer a fish is confined in a livewell [35]. A similar effect could be manifested in our models.

Signs of barotrauma rarely appeared in both species $(<$ $10 \%$ ) during this study. The percentage of fish exhibiting barotrauma in Lake Champlain tournaments was comparable to percentages observed in other studies, which indicate that instances of severe barotrauma can range from $1.9 \%$ on shallow lakes to $56.5 \%$ on deeper lakes $[28,29,33]$. Although 
Table 4. Standard Deviation, z-values, and p-values for Model Parameters. The Best Fitting Model is Displayed in Bold Font

\begin{tabular}{|c|c|c|c|c|c|c|c|}
\hline \multicolumn{4}{|c|}{ Smallmouth Bass } & \multicolumn{4}{|c|}{ Largemouth Bass } \\
\hline $\begin{array}{c}\text { Model } \\
\text { Parameters }\end{array}$ & SE & $\mathbf{z}$ & $\mathbf{p}$ & $\begin{array}{c}\text { Model } \\
\text { Parameters }\end{array}$ & SE & $\mathbf{z}$ & $\mathbf{p}$ \\
\hline \multicolumn{4}{|c|}{$\underline{\text { Baro } \sim \text { Temp }}$} & \multicolumn{4}{|c|}{$\underline{\text { Baro } \sim \text { SqrtDist }+ \text { Temp }}$} \\
\hline Intercept & 0.744 & -5.477 & $<0.01$ & Intercept & 0.972 & -8.620 & $<0.01$ \\
\hline Temp & 0.039 & 2.533 & 0.011 & SqrtDist & 0.042 & 2.326 & 0.02 \\
\hline & & & & Temp & 0.047 & 5.639 & $<0.01$ \\
\hline \multicolumn{8}{|c|}{$\underline{\text { Baro } \sim \text { Temp }+ \text { Length }}$} \\
\hline Intercept & 1.175 & -4.764 & $<0.01$ & \multicolumn{4}{|c|}{$\underline{\text { Baro } \sim \text { SqrtDist }+ \text { Temp }+ \text { Length }}$} \\
\hline Temp & 0.039 & 2.469 & 0.013 & Intercept & 1.345 & -7.142 & $<0.01$ \\
\hline Length & 0.002 & 1.691 & 0.091 & SqrtDist & 0.042 & 2.048 & 0.041 \\
\hline & & & & Length & 0.002 & 1.337 & 0.181 \\
\hline \multicolumn{4}{|c|}{$\underline{\text { Baro } \sim \text { SqrtDist }+ \text { Temp }+ \text { Length }}$} & Temp & 0.047 & 5.656 & $<0.01$ \\
\hline Intercept & 1.197 & -4.831 & $<0.01$ & & & & \\
\hline SqrtDist & 0.065 & 0.743 & 0.457 & \multicolumn{4}{|c|}{ WoundEx $\sim$ SqrtDist + Length + Temp } \\
\hline Length & 0.002 & 1.637 & 0.102 & Intercept & 1.428 & -3.838 & $<0.01$ \\
\hline Temp & 0.039 & 2.450 & 0.014 & SqrtDist & 0.056 & 4.246 & $<0.01$ \\
\hline & & & & Length & 0.003 & 2.586 & $<0.01$ \\
\hline \multicolumn{4}{|c|}{$\underline{\text { WoundEx } \sim \text { SqrtDist }+ \text { Temp }}$} & Temp & 0.051 & 4.061 & $<0.01$ \\
\hline Intercept & 0.669 & -3.075 & $<0.01$ & & & & \\
\hline SqrtDist & 0.587 & 3.198 & $<0.01$ & & & & \\
\hline Temp & 0.332 & 4.738 & $<0.01$ & & & & \\
\hline \multicolumn{4}{|c|}{$\underline{\text { WoundEx } \sim \text { SqrtDist }+ \text { Length }+ \text { Temp }}$} & & & & \\
\hline Intercept & 0.976 & -2.655 & $<0.01$ & & & & \\
\hline SqrtDist & 0.058 & 3.178 & $<0.01$ & & & & \\
\hline Length & 0.001 & 0.755 & 0.451 & & & & \\
\hline Temp & 0.033 & 4.717 & $<0.01$ & & & & \\
\hline \multicolumn{4}{|c|}{$\underline{\mathrm{LW} \sim \text { Length }}$} & & & & \\
\hline Intercept & 1.991 & -4.713 & $<0.01$ & & & & \\
\hline Length & 0.004 & 2.973 & $<0.01$ & & & & \\
\hline
\end{tabular}

Lake Champlain has an average depth of $19.5 \mathrm{~m}$, that number is skewed by the deep trenches in the Main Lake, an area rarely frequented by bass anglers $(<1 \%$ of fishes in this study came from that area of the lake). Discounting the Main Lake, Lake Champlain's average depth is approximately $6 \mathrm{~m}$. On the St. Lawrence River, incidence of barotrauma began to increase gradually at $6 \mathrm{~m}$ and did not increase dramatically until depths over $10 \mathrm{~m}$ [28]. Only $30 \%$ of fish in that study exhibited barotrauma. Studies of the relationship between barotrauma and mortality in catch and release, freshwater settings have found that between $10-20 \%$ of fish exhibiting signs of barotrauma (external indicators as well as blood 
chemistry changes) die as a result $[29,35]$. Given the relatively low percentage of fish arriving at Plattsburgh tournaments exhibiting barotrauma, it is likely a minimal contributor to tournament-related mortality.

A majority of both species (64\% of largemouth and 55\% of smallmouth) exhibited bloody fins. In many studies, hemorrhaging in fish fins is categorized as an indicator of barotrauma $[28,29,33]$. In our study, bloody fins were not significantly correlated with any other indicators of barotrauma. Rather, instances of bloody fins were correlated with wounds (e.g. fin damage) and indicators of exhaustion (e.g. absence of restraint resistance). From our models, it is apparent that wounding and exhaustion in both species are closely related to the water temperature and the square-root of distance traveled, which raises the possibility that bloody fins may actually be a result of transportation in a livewell. Further literature surveys revealed differences in methodology that lend further credence to this hypothesis. A comparison of three studies on waters in northeastern North America (Morrissey et al. [33] on Lake Erie, Gravel and Cooke [29] on Rainy Lake in Ontario, and Schreer et al. [28] on the St. Lawrence River) found similar levels of bloating (27\% - 41\%). Morrissey et al. [33] and Gravel and Cooke [29] also had similar levels of hemorrhaging $(62 \%-66 \%)$, but Schreer et al. [28] had much lower levels of hemorrhaging $(<4 \%)$. These studies differed in methodology such that Morrissey et al. [33] and Gravel and Cooke [29] both evaluated fishes following transportation from their point of capture to a central weighin location. In contrast, Schreer et al. [28] evaluated fish immediately after capture, before they were placed into a livewell. Our observations of hemorrhaging (59\%) are similar to those of Morrissey et al. [33] and Gravel and Cooke [29], and we also evaluated fish after livewell transport. The combination of the low occurrence of hemorrhaging in Schreer et al. [28] as well as our modeling showing a relationship between bloody fins, other wounds, indicators of exhaustion, and distance traveled in a livewell all suggests that hemorrhaging may be associated with livewell stress rather than barotrauma.

The likelihood of fish exhibiting wounding and indicators of exhaustion increased with distance traveled in a livewell ( $p$ $<0.01$ for both species). Previous studies using blood chemistry and video footage have documented that hauling is stressful for fish. Transported fish were found to have higher levels of plasma glucose and corticosteroids [9]. Corticosteroids are produced in response to exertion and stress, so elevated levels of these compounds is consistent with research that documents considerable energy expenditure by largemouth bass while avoiding collisions with other fish or livewell walls during transport [11]. Such collisions can result in dermal and ocular lesions, opening a vector for infections (a potential source of delayed mortality). Additionally, poor water quality and hypoxic conditions in livewells are often contributors to postrelease mortality during tournaments $[8,13]$.

Lamprey wounding was rare in this study $(<2 \%$ of fishes), and the majority of fishes exhibiting lamprey wounds were smallmouth bass. Low rates of lamprey wounding were expected because sea lamprey preferentially feed on fish with cycloid scales (e.g. salmonids) rather than fish with ctenoid scales (e.g. centrarchids) [36]. Addition- ally, in our models, length was a significant predictor ( $\mathrm{p}<$ 0.01 ) of exhibiting lamprey wounds in smallmouth bass. This is consistent with laboratory studies that show lamprey preferentially feeding on larger fish [37]. As expected, lamprey wounding was not related to distance traveled in a livewell or water temperature, because whether a fish has lamprey wounds or not is unrelated to its capture and handling in a tournament.

Temperature was a significant predictor of stress (both barotrauma and wounding/exhaustion) in both species (Table 4). This finding is consistent with current research using blood chemistry. Lower temperatures during fish hauling resulted in lower levels of stress (lower concentrations of corticosteroids and plasma glucose) post- release [9]. Furthermore, Ostrand et al. [13] found that initial physiological disturbance and delayed mortality were both higher when angling was conducted at higher ambient water temperatures. Although some studies found that other factors (e.g. levels of temperature changes, air exposure time) may play a larger role in fish stress than in situ lake temperature, a review and synthesis of numerous studies suggests there is a strong relationship between higher water temperatures and higher levels of tournament induced mortality, resulting from the cumulative effect of sub-lethal stressors [38]. Other studies report even low levels of stress resulting from increased water temperature can cause noticeable changes in behavior (e.g. loss of equilibrium, impaired swimming ability) $[15,17]$.

Another way water temperature can influence stress is by impacting tournament organizers' abilities to keep water temperatures consistent across infrastructure (i.e. livewells, storage tanks, release boats). Other research has found that being transferred to water that has significantly elevated or significantly reduced temperatures impaired recovery of tissue lactate and tissue ATP in largemouth bass [17]. In our study, fishes were evaluated in our holding tanks after having passed through livewells and tournament holding tanks, but before entering the release boat. On all 2012 tournament days, temperatures in our holding tanks were statistically similar to temperatures in the release boat (Fig. 3). However, on the three hottest tournament days temperatures in the tournament holding tanks were significantly lower than temperatures in our holding tanks and the release boat. Tournament organizers on those days added ice to their holding tanks in an effort to keep them from overheating. However, this practice may do more harm than good [13].

\section{CONCLUSION}

Our findings are consistent with existing research on fish stress using blood chemistry, indicating that physical signs of stress can be used to evaluate fish condition at tournaments, where the need to process large numbers of fish may make blood chemistry financially or temporally prohibitive. Further research should address the relationships between stress indicators and mortality (both immediate and delayed) as well as relationships between physical indicators of stress and physiological indicators of stress. These relationships could be assessed by evaluating fish in a variety of conditions at tournaments using physical metrics and blood chemistry analysis, and following the fish for several days after release using telemetry. Knowledge of these relationships 
would enable tournament organizers to evaluate fish prior to release. This would ensure that only healthy fish with a good chance of recovering would be released, reducing the likelihood of fish kills following tournament events.

\section{CONFLICT OF INTEREST}

The authors confirm that this article content has no conflicts of interest.

\section{ACKNOWLEDGEMENTS}

We would like to acknowledge funding support from the NYSDEC and the Lake Champlain Basin Program. Additionally, we would like to thank Siobhan Levere, Erin Malchoff, Erica Gorey, Rick Perry, Erin Hayes-Pontius, GayanJayasinghe, MarkLaMay, the City of Plattsburgh, SUNY Plattsburgh students who volunteered, and all anglers and tournaments who allowed us access to their fish.

\section{REFERENCES}

[1] Connelly NA, Brown TL. New York statewide angler survey, 2007 report 1: angler effort and expenditures. New York State Dep Environ Conserv Bur Fish Albany NY 2009.

[2] Edwards GP Jr, Neumann RM, Jacobs RP, O’Donnell EB. Impacts of small club tournaments on black bass populations in Connecticut and the effects of regulation exemptions. North Am J Fish Manag 2004; 24 : 811-21.

[3] Hall J, Jones DH, Bitz K. 100 Best Bass Lakes. Bassmaster 2012.

[4] Lake Champlain Fisheries Technical Committee, Strategic plan for Lake Champlain fisheries, Lake Champlain Fish Wildl.Manag. Coop. USFWS 2009.

[5] HaslerAD, Wisby WJ. The return of displaced largemouth bass and green sunfish to a "home" area. Ecology 1958; 39: 289-93.

[6] Wells RM, McIntyre R, Morgan A, Davie P. Physiological stress responses in big gamefish after capture: observations on plasma chemistry and blood factors. Comp Biochem Physiol A Physiol 1986; 84: 565-71.

[7] Gustaveson AW, Wydoski RS, Wedemeyer GA. Physiological response of largemouth bass to angling stress. Trans Am Fish Soc 1991; 120: 629-36.

[8] Furimsky M, Cooke, SJ, Suski CD, Wang Y, Tufts BL. Respiratory and circulatory responses to hypoxia in largemouth bass and smallmouth bass: implications for "live-release" angling tournaments. Trans Am Fish Soc 2003; 132: 1065-75.

[9] Carmichael GJ, Tomasso JR, Simco BA, Davis KB. Characterization and alleviation of stress associated with hauling largemouth bass. Trans Am Fish Soc 1984; 113: 778-85.

[10] Davis MW, Schreck CB. Responses by Pacific halibut to air exposure: lack of correspondence among plasma constituents and mortality, Trans Am Fish Soc 2005; 134: 991-8.

[11] Suski CD, Cooke SJ, Killen SS, PHILIPP W, Tufts BL. Behaviour of walleye, Sander vitreus, and largemouth bass, Micropterussalmoides, exposed to different wave intensities and boat operating conditions during livewell confinement. Fish Manag Ecol 2005; 12: 19-26.

[12] Burleson ML, Wilhelm DR, Smatresk NJ. The influence of fish size on the avoidance of hypoxia and oxygen selection by largemouth bass. J Fish Biol 2001; 59: 1336-49.

[13] Ostrand KG, Siepker MJ, Wahl DH. Effectiveness of livewell additives on largemouth bass survival. J Fish Wildl Manag 2011;2: 22-8.

[14] Kieffer JD. Limits to exhaustive exercise in fish. Comp Biochem Physiol 2000; 126: 161-79.
[15] Gingerich AJ, Cooke SJ, Hanson KC, et al. Evaluation of the interactive effects of air exposure duration and water temperature on the condition and survival of angled and released fish. Fish Res 2007; 86: 169-78.

[16] Thompson LA, Cooke SJ, Donaldson MR, et al. Physiology, behavior, and survival of angled and air-exposed largemouth bass. North Am J Fish Manag 2008; 28: 1059-68.

[17] Suski CD, Killen SS, Kieffer JD, Tufts BL. The influence of environmental temperature and oxygen concentration on the recovery of largemouth bass from exercise: implications for live-release angling tournaments. J Fish Biol 2006; 68: 120-36.

[18] Van Landeghem MM, Wahl DH, Suski CD. Physiological responses of largemouth bass to acute temperature and oxygen stressors. Fish Manag Ecol 2010; 17: 414-25.

[19] Arlinghaus R, Klefoth T, Cooke SJ, Gingerich A, Suski C. Physiological and behavioural consequences of catch-and-release angling on northern pike (Esoxlucius L.). Fish Res 2009; 97: 223-33.

[20] Davis MW, Ottmar ML. Wounding and reflex impairment may be predictors for mortality in discarded or escaped fish. Fish Res 2006; 82: 1-6.

[21] Davis MW. Fish stress and mortality can be predicted using reflex impairment. Fish Fish 2010; 11: 1-11.

[22] Campbell MD, Patino R, Tolan J, Strauss R, Diamond SL. Sublethal effects of catch-and-release fishing: measuring capture stress, fish impairment, and predation risk using a condition index, ICES J Mar Sci J Cons 2010; 67: 513-21.

[23] Quantum GIS Development Team. Quantum GIS “Lisboa,” Open Source Geospatial Foundation Project, 2012.

[24] McCune B, Grace JB, Urban DL. Analysis of ecological communities. Oregon: MjM Software Design Gleneden Beach 2002.

[25] Zuur AF, Ieno EN, Meesters E. A Beginner's Guide to R. Springer 2009.

[26] R Core Team R. A Language and Environment for Statistical Computing, R Foundation for Statistical Computing, Vienna: Austria 2012.

[27] R Studio Development Team. Boston, MA: R Studio 2012.

[28] Schreer JF, Gokey J, DeGhett VJ. The incidence and consequences of barotrauma in fish in the St. Lawrence River. North Am J Fish Manag 2009; 29: 1707-13.

[29] Gravel M, Cooke SJ. Severity of barotrauma influences the physiological status, postrelease behavior, and fate of tournament-caught smallmouth bass. North Am J Fish Manag 2008; 28 (2): 607-17.

[30] Hayes DB, Taylor WW, Soranno PA. Natural lakes and large impoundments. In: Inland Fish Manag North Am, $2^{\text {nd }}$ ed. Bethesda, Maryland: American Fisheries Society 1999: pp. 592-5.

[31] Edwards EA, Gebhart G, Maughan OE. Habitat suitability information: smallmouth bass. Washington: US Fish and Wildlife Service 1983.

[32] Bersell PO. Vertical distribution of fishes relative to physical, chemical, and biological features in two central Arizona reservoirs. Thesis. Arizona: Arizona State University 1973.

[33] Morrissey MB, Suski CD, Esseltine KR, Tufts BL. Incidence and physiological consequences of decompression in smallmouth bass after live-release angling tournaments. Trans Am Fish Soc 2005; 134: 1038-47.

[34] Suski CD, Killen SS, Cooke SJ, Kieffer JD, Philipp DP, Tufts BL. Physiological significance of the weigh-in during live-release angling tournaments for largemouth bass. Trans Am Fish Soc 2004; 133: 1291-303.

[35] Roach JP, Hall KC, Broadhurst MK. Effects of barotrauma and mitigation methods on released Australian bass Macquarianovemaculeata. J Fish Biol 2011; 79: 1130-45.

[36] Farmer GJ. Biology and physiology of feeding in adult lampreys. Can J Fish Aquat Sci 1980; 37: 1751-61.

[37] Farmer GJ, Beamish FWH, Robinson GA. Food consumption of the adult landlocked sea lamprey, Petromyzonmarinus, L. Comp Biochem Physiol A Physiol 1975; 50: 753-7.

[38] Wilde GR. Tournament-associated mortality in black bass. Fisheries 1998; 23: 12-22. 